\title{
A critique of Armstrong's truthmaking account of possibility
}

Kalhat, Javier

\begin{abstract}
In this paper I argue against Armstrong's recent truthmaking account of possibility. I show that the truthmaking account presupposes modality in a number of different ways, and consequently that it is incapable of underwriting a genuine reduction of modality. I also argue that Armstrong's account faces serious difficulties irrespective of the question of reduction; in particular, I argue that his Entailment and Possibility Principles are both false. Keywords: Armstrong - Truthmakers - Possibility - Reduction - Instantiation - Combinatorialism
\end{abstract}

DOI: https://doi.org/10.1007/s12136-008-0027-z

Posted at the Zurich Open Repository and Archive, University of Zurich ZORA URL: https://doi.org/10.5167/uzh-17317

Journal Article

Published Version

Originally published at:

Kalhat, Javier (2008). A critique of Armstrong's truthmaking account of possibility. Acta Analytica, 23(2):161-176.

DOI: https://doi.org/10.1007/s12136-008-0027-z 


\title{
A Critique of Armstrong's Truthmaking Account of Possibility
}

\author{
Javier Kalhat
}

Received: 6 March 2008 / Accepted: 26 May 2008 /Published online: 20 June 2008

(C) Springer Science + Business Media B.V. 2008

\begin{abstract}
In this paper I argue against Armstrong's recent truthmaking account of possibility. I show that the truthmaking account presupposes modality in a number of different ways, and consequently that it is incapable of underwriting a genuine reduction of modality. I also argue that Armstrong's account faces serious difficulties irrespective of the question of reduction; in particular, I argue that his Entailment and Possibility Principles are both false.
\end{abstract}

Keywords Armstrong · Truthmakers · Possibility · Reduction · Instantiation · Combinatorialism

Armstrong's thinking on modal matters has continued to develop since the publication of $A$ Combinatorial Theory of Possibility (1989a). In subsequent work - A World of States of Affairs (1997) and in particular Truth and Truthmakers (2004) - Armstrong has become more explicitly concerned with the task of providing suitable 'truthmakers' for modal truths. In this paper I critically examine Armstrong's truthmaking account of possibility. It will become clear that Armstrong's new account is incompatible with the combinatorial theory he previously defended. A central aim of the combinatorial theory was to achieve a reduction of modality, and Armstrong has indeed been, together with David Lewis (1986), a prominent champion of modal reductionism. ${ }^{1}$ It is therefore an important question whether Armstrong's new truthmaking account of possibility is genuinely reductive. I will argue that it is not: the account presupposes modality in a number of different ways. In all fairness to

\footnotetext{
${ }^{1}$ Combinatorialism 'traces the very idea of possibility to the idea of the combinations - all the combinations - of given, actual elements', namely universals and particulars (1989a: 37; see also, 1997). The theory is intended to be reductive of the notion of possibility, since the latter 'is given an analysis, an analysis which uses the universal quantifier' (1989: 47), i.e., which merely uses the universal quantifier.
}

J. Kalhat $(\bowtie)$

Philosophisches Seminar, Universität Zürich, Zürichbergstrasse 43, 8044 Zürich, Switzerland e-mail: kalhat@philos.uzh.ch 
Armstrong, it is no longer clear that he seeks a reduction of modality. (As we shall see, for example, his new view concerning the nature of instantiation introduces a thick layer of necessity into the world, and he is perfectly aware of this.) I do not claim, therefore, to undermine Armstrong's aspirations on the matter, but rather to show that, whatever those aspirations are, his account fails to be genuinely reductive. Finally, I argue that Armstrong's account faces serious difficulties irrespective of the question of reduction; in particular, I show that his Entailment and Possibility Principles are both false.

\section{Truthmaking Theory and Its Account of Possibility}

Armstrong takes propositions to be the bearers of truth (2004: 12-16). Propositions are the intentional objects of possible or actual beliefs, thoughts and sentences. They are abstractions from those beliefs, thoughts and sentences; they are types rather than tokens - i.e., they are universals.

Every true proposition has a truthmaker (truthmaker maximalism). A truthmaker is that which makes a proposition true. In the case of ordinary truths, truthmakers are portions of the world, namely, states of affairs. Thus, what makes the proposition, e.g., <The Eiffel Tower is 990 feet tall $>^{2}$ true is neither the Eiffel Tower (which has many other properties as well), nor the property of being 990 feet tall (which the Eiffel Tower could fail to have), but rather the state of affairs of the Eiffel Tower's being 990 feet tall. Some true propositions do have, however, objects rather than states of affairs as their truthmakers. These include, in particular, propositions asserting the existence of the objects in question (e.g., $<$ David Armstrong exists $>$ ), and necessary truths. ${ }^{3}$

When we ask for the truthmaker for a true proposition, we ideally want what Armstrong calls a minimal truthmaker - that is, we want the specific portion of reality that is responsible for the truth of that particular proposition. More specifically still, if ' $\mathrm{T}$ is a minimal truthmaker for $p$, then you cannot subtract anything from $T$ and the remainder still be a truthmaker for $p^{\prime}$ (2004: 19-20).

According to Armstrong, then, truth-bearers are propositions and truthmakers are (typically) states of affairs. What about the relation of truthmaking itself? What kind of relation is it? Armstrong has several things to say about it. First, it is not a oneone relation. One truthmaker can make many truths true, and conversely one truth can have many truthmakers.

Secondly, truthmaking is not a causal making. A state of affairs does not cause a proposition to be true in the way in which, say, dropping a piece of glass against a hard surface causes it to break. In Armstrong's view, 'the best formulation of what this making is seems to be given by the phrase 'in virtue of'. It is in virtue of that independent reality that the proposition is true. What makes the proposition a truth is how it stands to this reality' (2004: 5).

\footnotetext{
${ }^{2}$ I follow Armstrong (and others) in using ' $<>$ ' to pick out propositions.

${ }^{3}$ For Armstrong's truthmaking account of necessary truth, which will not concern us here, see Armstrong 2004: Ch. 8. 
Thirdly, the relation of truthmaking 'is necessitation, absolute necessitation' (2004: 5). A truthmaker necessitates the truth of the proposition it makes true (truthmaker necessitarianism). Truthmaking is not logical entailment, however. The latter holds between propositions, whereas truthmaking is a cross-categorial relation, one that links propositions with portions of the world.

Fourthly, as a relation of necessitation, truthmaking is an internal relation, i.e., it is a relation that is necessitated by its relata. Thus, 'given a certain real object, and a certain proposition, in that order, then the truthmaking relation ... is automatically determined, fixed, necessitated' (2004: 9). This has an important consequence. Armstrong defends what he calls 'the doctrine of the ontological free lunch', according to which if an entity $\mathrm{X}$ supervenes on an entity $\mathrm{Y}$, then $\mathrm{X}$ is no addition of being to $\mathrm{Y}$ (which is not to say that $\mathrm{X}$ does not exist) (Armstrong 1997: 12-3). In Armstrong's view, internal relations are a paradigm example of supervening entities. As an internal relation, therefore, truthmaking is no addition of being to its relata, a truthmaker and a proposition.

\subsection{The Entailment Principle}

A central thesis of Armstrong's truthmaking theory is what he calls 'the Entailment Principle'. This principle says that if $T$ is a truthmaker for a proposition $p$, and $p$ entails a proposition $q$, then $T$ is also a truthmaker for $q$. The notion of entailment employed here is not classical entailment (i.e., strict implication). A contingent proposition classically entails every necessary truth. But if $p$ above is a contingent proposition and $q$ a necessary truth, then by the Entailment Principle the truthmaker for $p$ is also a truthmaker for $q$. 'This', says Armstrong, 'robs truthmaking theory of all interest for the case of necessary truths' (2004: 11). One option, then, is to place restrictions on the relation of entailment to prevent a contingent proposition from entailing every necessary proposition. This option leads to a non-classical version of entailment. Alternatively, and building on a suggestion by Jackson, we can restrict the kind of propositions among which the entailment relation holds to those that are 'purely contingent' - i.e., propositions that are not necessary and do not contain any necessary conjuncts (at any level of analysis) (Armstrong 2004: 11). As we shall see later on, the Entailment Principle plays a crucial role in Armstrong's provision of truthmakers for truths of possibility.

\subsection{The Necessity of Instantiation}

Armstrong has had a 'change of heart' concerning the nature of the instantiation of universals by particulars. Armstrong had previously 'conceived of instantiation as a matter of contingent connection of particulars with universals' (2004: 46). Influenced by Baxter (2001), however, he now conceives of instantiation as a case of partial identity. He says that it is not a 'mere mereological overlap', but nevertheless it is partial identity. Baxter regards the partial identity between a particular and a universal as a contingent matter, but Armstrong thinks that this is a mistake. Partial identity is necessary, since, following Kripke, he regards all identity as necessary rather than contingent (2004: 80). Suppose, then, that a particular $a$ has a universal $F$. If the state of affairs is contingent, then it might not have existed. If it 
had not existed, then $a$ would not have existed either, for it would have lacked the intersection with $F$. Something like $a$ - a 'counterpart' of $a$-might have existed. But that counterpart would not be strictly identical with $a$ since it would lack the intersection with $F$. What goes for the particular $a$ also goes for the universal $F$. If the state of affairs of $a$ 's being $F$ had not existed, then neither would the universal $F$. For, again, the intersection with $a$ would be missing. There could have been a universal very much like $F$ - a counterpart of $F$ - but it would not be $F$. Armstrong regards $a$, $F$, and the state of affairs of $a$ 's being $F$ all as contingent beings. But given that $a$ and $F$ both exist, and that $a$ is $F$, then a must be $F$. There is 'a necessary connection between contingent beings' (2004: 47).

\subsection{The Possibility Principle}

The philosophically interesting cases of possibilities are those presented by contingent falsities. A contingent proposition $p$ is one where both $p$ and its contradictory not- $p$ are possible. Armstrong calls contingent falsehoods 'mere possibilities'. The challenge is to find suitable truthmakers for true mere possibilities.

In his combinatorialist phase, Armstrong had claimed that possible worlds, fictionally construed, provide suitable truthmakers for truths of possibility. "II is possible that $p$ " is true if and only if there is a possible world where $p$ is true' (1989a: 51). But Armstrong 1997 came to see that account as 'misguided' (1997: 172). The truthmakers for truths of possibility are nothing but actual (contingent) states of affairs, and ultimately their constituent particulars and universals. Armstrong 2004 further develops this idea.

Take a contingent truth $p$. Its negation, not- $p$, is false. But the possibility of not- $p$ is true. For every contingent truth, the possibility of its negation is also true. This is guaranteed, says Armstrong, by the nature of contingency. So, given $p$ and given that $p$ is contingent, the truth of $<\mathrm{It}$ is possible that not- $p>$ is entailed. Armstrong now applies the Entailment Principle, which delivers the result that the truthmaker for $<$ It is possible that not- $p>$ is the same as the truthmaker for $p$ itself. 'It seems reasonable to say that a truthmaker for a contingent truth is also a truthmaker for the truth that the contradictory of that truth is possible' (2004: 84). This applies as much to positive contingent truths (i.e., ones stating that something is case) as to negative truths (i.e., ones stating that something is not the case). Thus, the truthmaker for every truth of mere possibility is a truthmaker for its contradictory. Armstrong calls this the 'Possibility Principle' (2004: 85).

\subsection{Truthmakers for the Possibility of Aliens}

In a rather ironic turn of events, the possibility of alien particulars and universals is one of the few possibilities that Armstrong can now admit given his new view of instantiation. Alien particulars and universals are ones that are not found in the actual world, and are not combinatorially constructible from those that are (Armstrong 2004: 86-9). Given Armstrong's new thinking on instantiation, all non-existent particulars and universals are ipso facto alien particulars and universals. For no existent particulars and no existent universals could combine to yield the non-existent ones.

算 Springer 
Since Armstrong upholds the possibility of alien particulars and universals, he must find a suitable truthmaker for their possibility. His suggestion rests on two premises. The first is the Possibility Principle, according to which the truthmaker for a contingent truth is also a truthmaker for the possibility of its contradictory. The second premise rests on Armstrong's account of general (contingent) truths, i.e., truths of the form $<$ This aggregate of $x \mathrm{~s}$ are all the $x \mathrm{~s}>$ (Armstrong 2004: Ch. 6). For such truths, Armstrong offers states of affairs of totality as truthmakers. Briefly, suppose that there are $n$ electrons in the universe. Then the truthmaker for this truth is the state of affairs of $n$ electrons, being all the electrons there are. Now consider the true proposition $<\mathrm{A}$ certain group of particulars and universals are all the particulars and universals there are $>$. Since this proposition is contingent, it entails the possibility of its contradictory, which is precisely the proposition that there might have been more (and hence alien) particulars and universals - i.e., the proposition $<$ Alien particulars and universals are possible $>$. But now the Possibility Principle can be applied. The truthmaker for the latter proposition will be the truthmaker for the proposition that a certain group of particulars and universals are all the particulars and universals there are, viz., the totality state of affairs of those particulars and universals' being all the particulars and universals.

This concludes my exposition of Armstrong's truthmaking account of possibility. I will now argue that the account presupposes modality at a number of key points, and hence is incapable of underwriting a genuine reduction of modality. I will also show that Armstrong's account fails on its own terms. Both the Entailment and Possibility Principles are false, and hence Armstrong has failed to provide suitable truthmakers for truths of mere possibility.

\section{Is The Relation of Truthmaking Modal in Nature?}

As characterized by Armstrong, the relation of truthmaking presupposes modality in several ways. First, Armstrong explicitly says that truthmaking is a relation of necessitation. As a truthmaker necessitarian, Armstrong maintains that if $T$ is a truthmaker for $p$, then $T$ necessitates the truth of $p$. The relation of necessitation involved here is neither causal nor logical, but rather metaphysical. If Armstrong treats that relation as modally primitive, then truthmaker theory cannot sustain a genuine reduction of modality. The challenge for Armstrong is thus to find a way of grounding the modality involved in the truthmaking relation in some feature of $T$ (and perhaps of $p$ ) that is itself non-modal. It is difficult to see how Armstrong can meet this challenge, since if $T$ necessitates $p$, then whatever feature of $T$ explains this will be necessary to $T$. Otherwise, $T$ could exist without it, and a fortiori $T$ could exist without necessitating the truth of $p$ - which would violate Armstrong's truthmaker necessitarianism.

Secondly, the truthmaking relation has a counterpart running in the opposite direction which is also a relation of necessitation. Take $p$ to be the true proposition $<$ Armstrong exists $>$. Its truthmaker is Armstrong himself. Now, just as Armstrong necessitates the truth of $<$ Armstrong exists $>$, so (in accordance with truthmaker maximalism) <Armstrong exists $>$ necessitates the existence of a truthmaker, which in this case is Armstrong himself. We can call the necessitating of a truthmaker by the relevant true proposition, 'existence-making'. Just as $T$ makes 
for the truth of $p, p$ makes for the existence of $T$, so to speak. ${ }^{4}$ The same challenge applies here as before. The kind of necessitation involved in existence-making is metaphysical in nature, and unless it can be grounded in some non-modal feature of $p$ (and perhaps $T$ ), truthmaker theory will be unable to sustain a genuine reduction of modality. But whatever feature of $p$ we single out will be a necessary feature of $p$. Otherwise, $p$ could exist without it, and a fortiori $p$ could exist without necessitating the existence of $T$.

The modal nature of truthmaking can also be brought out in the following way. Armstrong claims not only that a truthmaker $T$ necessitates the truth of the relevant proposition $p$, but also that the joint existence of $T$ and $p$ necessitates the existence of a relation of truthmaking holding between them. Thus, not only is truthmaking a relation of necessitation; truthmaking is itself necessitated by its relata. The same challenge applies here as in the previous two cases. What is it about a true proposition $p$ and its truthmaker $T$, such that the mere existence of $p$ and $T$ necessitates the existence of a relation of truthmaking holding between them? An adequate answer to this question will appeal to features of $p$ and $T$. But whatever those features are, $p$ and $T$ must have them necessarily. For otherwise, $p$ and $T$ could exist without them, and a fortiori $p$ and $T$ could exist without giving rise to a relation of truthmaking holding between them - in violation of the internality of the truthmaking relation.

In earlier work, Armstrong attempted to ground internal relations in 'nothing more than the identity and difference' of their relata, adding that 'the identity may be mere partial identity, which is, of course, at the same time mere partial difference' (1997: 89; see also 2004: 103-104). Armstrong illustrates what he has in mind here by focusing on the internal relation of resemblance. If two particulars $a$ and $b$ resemble each other, then they will do so by virtue of instantiating the same, identical universal, say, $F$. Their resemblance is thus grounded in their partial identity, i.e., in their common possession of the universal $F$.

Armstrong does not offer a parallel illustration for the case of truthmaking. But since truthmaking is also an internal relation, it is presumably similarly grounded in the identity (difference) of its relata. What features of those relata could he appeal to here? Marian David has taken up this question (2002). Let $T$ be the state of affairs $a$ 's being $F$ and $p$ the proposition that $a$ is $F$. $T$ makes $p$ true. What feature might $T$ and $p$ share so as to ground the truthmaking relation they jointly necessitate? There are three main possibilities. The first is that $T$ and $p$ share the same structure, and it is that structure that grounds the truthmaking relation. This will not do, however, since many propositions can have the same structure as $p$ (e.g., the proposition that $b$ is $G$ ) without being made true by $T$ (but instead by some other truthmaker with the same structure, e.g., $b$ 's being $G$ ). A second possibility is that $T$ and $p$ share not only their structure but also their constituents. $T$ consists of a particular $a$ and a universal $F$. If we take $p$ to be similarly constituted, however, then $T$ and $p$ come out as identical, which Armstrong would reject. He takes truthmaking to be a cross-categorial relation. If $p$ and $T$ belong to different categories, then they can hardly be identical. A third possibility is to say that $T$ and $p$ share structure plus one of their constituents. Perhaps $p$ is constituted by the particular $a$ and a concept $F$ (rather than the universal $F$ ). The

\footnotetext{
${ }^{4}$ Like truthmaking, existence-making is not a causal making.

型 Springer
} 
trouble with this is that other propositions, including false ones, can be partially identical with $T$ in this way. Suppose that $a$ is not $G$. Then the proposition that $a$ is $G$ is false. Yet that proposition is partially identical with $T$. This sort of partial identity between $T$ and $p$, therefore, does not suffice to ground the truthmaking relation that holds between them. Having ran out of possibilities for grounding the truthmaking relation, David concludes:

Is [Armstrong], then, content with saying that there is nothing more to say than just this: the state of affairs being what it is, and the proposition being what it is, the truthmaking relation must hold between them? (2002: 156)

I think this is all that Armstrong can in fact say. He must take the necessitation of the truthmaking relation by its relata as primitive. Accordingly, even if Armstrong succeeds in providing non-modal truthmakers for modal truths, he will not have eliminated all primitive modality. Some will remain implicated in the relation of truthmaking itself. This prevents truthmaking theory from delivering a genuine reduction of modality.

\section{Problems with Armstrong's New View of Instantiation as Partial Identity}

An important consequence of Armstrong's new view of instantiation as partial identity is that his truthmaking account is incompatible with the combinatorial theory of possibility he previously defended (1989a). The latter presupposes that particulars and universals can combine and recombine freely to yield all the possibilities. On the new thinking, this is no longer the case. Particulars and the universals they instantiate are partially identical, and necessarily so. Thus, suppose that a particular $a$ instantiates the universal $F$, and suppose too that it only instantiates that universal. Then, neither $a$ nor $F$ can be recombined in such a way that $a$ fails to instantiate $F$. Furthermore, neither $a$ nor $F$ can be recombined in such a way that $a$ instantiates some additional universal $G$, or such that $F$ is instantiated by some additional particular $b$. Particulars necessarily instantiate the universals they actually instantiate, and only those. Universals are necessarily instantiated by the particulars that actually instantiate them, and only by those. Neither could feature in a different instantiation. Hence, particulars and universals are no longer available for recombination in the way required by the combinatorial theory of possibility. ${ }^{5}$

Whether the clash between Armstrong's new view of instantiation and his previously espoused combinatorialism is a bad thing will depend on one's views about combinatorialism itself. But Armstrong's new view concerning instantiation has other, more problematic consequences. As we have just seen, Armstrong's new view of instantiation introduces a thick layer of necessity into the world, and contingency is all but completely vanished. As a result, most of our modal intuitions come out as strictly speaking false. No constituent of the world could have been different in any way at all, for all its actual ways of being are constitutive of its (numerical) identity. Thus, the Eiffel Tower could not have been even $1 \mathrm{~mm}$ taller than it actually is, I could not have failed to have pasta for lunch yesterday, you could not

\footnotetext{
${ }^{5}$ Armstrong thinks that a combinatorialist element is present in the provision of minimal truthmakers for possibilities concerning alien particulars and universals. We return to this in section 4 below.
} 
have had a different hair color, etc. Every true predication becomes a necessary truth (or at least those attributing genuine universals to particulars). Armstrong used to be an anti-essentialist (cf. 1989a: 51-53); he is now committed to an extreme ('Leibnizian') form of essentialism, one which includes mereological as well as property essentialism (Armstrong 2005: 274). ${ }^{6}$ This, of course, also prevents the truthmaking account from delivering a genuine reduction of modality. The motivating force behind truthmaking theory is that truth depends (or supervenes) on being. Thanks to Armstrong's new view of instantiation, however, that being is shot through with necessity.

Simons asks whether Armstrong's commitment to Leibnizian essentialism is worth paying for the benefit of having an account of instantiation (2005: 260). The situation is arguably worse than that, for it is unclear that Armstrong's new account sheds any real light on the nature of instantiation. The main advantage of Armstrong's view of instantiation as partial identity is supposed to be that it clarifies the nature of the relation between particulars and universals, which has traditionally been the Achilles heel of the two-category ontology. But Armstrong has not managed to spell out the precise sense in which a particular and the universals it instantiates are partially identical. Taken literally, partial identity means (strict) identity of the parts. Two entities can be partially identical in either of two ways: they can overlap, or one can be a proper part of the other. ${ }^{7}$ Two adjacent houses are partially identical in the first sense: they share a wall in common. Thus, one house has a part $a$ and the other house has a part $b$, and $a$ is strictly identical with $b$. A table and any one of its legs are partially identical in the second sense: the table has a proper part - the leg - and the leg has an (improper) part - itself - and the two are strictly identical.

But now in what sense are a particular $a$ and the universal $F$ that it instantiates partially identical? $a$ and $F$ cannot have a part in common. For suppose they did. Would that part be a particular or a universal? If the part in common is a particular, then the universal is partly particular. But this cannot be, since universals are repeatable entities but no particular is. If, on the other hand, the part in common is a universal, then the particular is partly universal. Now, it is true that some particulars, namely states of affairs, are partly composed of universals. However, the particulars that are supposed to be partially identical with universals are not states of affairs - what Armstrong calls 'thick particulars' - but rather thin particulars - particulars considered in abstraction from the universals they instantiate. Thin particulars cannot therefore have universals as parts. $^{8}$ A similar difficulty arises if we take particulars and universals to stand in the part/ whole relation instead. Either the particular is partly a universal, in which

\footnotetext{
${ }^{6}$ Armstrong attempts to accommodate our modal intuitions by endorsing a highly deflationary form of Lewis' counterpart theory. When we say, e.g., that the Eiffel Tower could have been $1 \mathrm{~mm}$ taller than it actually is, what we say is strictly speaking false. What is true, however, is that there could have been an object very much like the Eiffel Tower, which was $1 \mathrm{~mm}$ taller than the actual Eiffel Tower (2004: 47). We return to the topic of counterparts in section 4 below.

${ }^{7}$ On p. 103 of Truth and Truthmakers Armstrong himself glosses partial identity in this way (see also, 1997: 17-8).

${ }^{8}$ Could Armstrong now simply say that all particulars are thick ones? I do not think so, for he would then have to rethink his conception of states of affairs, and indeed his whole atomistic metaphysics. I assume that faced with this degree of revisionism, he would rather give up the view of instantiation that demands it.
}

Springer 
case it is not a thin particular. Or the universal is partly a particular, in which case it is not repeatable, and hence not really a universal.

The question remains, therefore, in what sense a particular and the universals it instantiates can be said to be partially identical. Armstrong often speaks of the 'intersection' of universals and particulars. He says that we can represent the new conception of universals and particulars 'as a table with the different particulars as the columns and the different universals as the rows'; then 'it can be seen that $a$ particular's having a property becomes an intersection of column and row' (2004: 48 ). But talk of intersections of columns and rows is metaphorical; it gives us a pictorial representation of the relation between universal and particular, whereas what we need is a direct characterization of that relation itself (which does not hold between columns and rows, needless to say).

In his contribution to a symposium on Truth and Truthmakers, Armstrong admits that 'partial identity' is 'a somewhat misleading phrase' (2005: 274). ${ }^{9}$ He says that universals are a 'special sort of part' of the particulars that instantiate them, that particulars 'enfold' their universals. But this is all terribly obscure. What 'special sort of part' is that? As for the notion of enfoldment, it is clearly metaphorical, and not very suggestive at that. Armstrong says that particulars enfold their universals, but universals do not enfold their particulars (the partial identity is thus no longer seen as symmetrical). But we simply do not have a sufficient grasp of what it might be for a particular to enfold the universals it instantiates to be able to assert or deny that universals do not similarly enfold their particulars. Until Armstrong clarifies the sense of partial identity he has in mind, the new view of instantiation cannot be seen as an advance over his earlier view, according to which instantiation is a 'non-relational tie' between particulars and universals (1989b: 108-110). ${ }^{10,11}$

\section{Minimal Truthmakers and Alien Possibilities}

Truthmaking theory naturally generates an expectation that truths will have minimal truthmakers. In Armstrong's preferred idiom, a truthmaker for a given proposition is that portion of reality in virtue of which the proposition is true. As an 'in-virtue-of' relation, truthmaking strongly suggests that its worldly relatum is some specific part of reality which is responsible for the truth of the proposition. And this points in the direction of minimal truthmakers, which, it will be recalled, are ones where nothing

\footnotetext{
${ }^{9} \mathrm{He}$ is responding to criticisms by Simons and Mumford; see Simons 2005 and Mumford 2005.

${ }^{10}$ Baxter, from whom Armstrong gets the idea of instantiation as partial identity, says that the partial identity of a universal with a particular is 'the identity of an aspect of [the] universal with an aspect of [the] particular ... The aspect is the part they have in common' (Baxter 2001: 453). Aspects are meant to be real entities; we refer to them through phrases such as 'insofar as', 'to the extent that', and 'qua', e.g., ' $\mathrm{x}$ insofar as it is $\mathrm{F}$ is H'. As far as I can tell, Armstrong does not endorse Baxter's theory of aspects. And this is a wise decision. For, despite Baxter's insistence to the contrary, the theory's 'underlying idea' that an entity can differ from itself without contradiction, that 'something can be true of one aspect of an entity that is false of another aspect of it, even though its aspects are numerically identical with it' remains obscure (Baxter 2001: 449; see also Simons 2005: 258-9).

${ }^{11}$ For other problematic consequences of Armstrong's new view of instantiation, including the so-called 'deletion problem', see Simons 2005 and Mumford 2005, 2007.
} 
can be subtracted from them while they remain truthmakers for the relevant propositions. Minimal truthmakers are, if you like, perfectly relevant to the truths of the propositions they make true; they are the most 'discerning' truthmakers of all (cf. Armstrong 2004: 18).

Armstrong attempts to provide minimal truthmakers for alien possibilities, i.e., possibilities involving particulars and/ or universals that are neither identical with, nor constructible out of, actually existing particulars and/ or universals. One such truth of alien possibility is $<\mathrm{It}$ is possible that a unicorn exists $>$. What is the minimal truthmaker for this proposition? 'The obvious solution', says Armstrong, 'is combinatorial' (2004: 91). The non-existent unicorn is a non-existent combination of actually existing elements, viz., horses and horns. Accordingly, says Armstrong, the mereological sum of any actual horse and any actual horn serves as a minimal truthmaker for the proposition that it is possible that a unicorn exists. The elements must be combinable of course, which raises the question of what the truthmaker for the truth $<$ Horns and horses are combinable $>$ is. Armstrong suggests again that the truthmaker is nothing but the sum of the elements themselves. 'Combinability is a relation but it is surely an internal relation, because given the elements, their combinability or non-combinability is necessitated by their nature. And the truthmakers for internal relations ... are just the terms of the relation' (2004: 92).

The situation, however, is not as straightforward as Armstrong thinks. Actual horns and actual horses are not in fact related in the way that is relevant for the possibility of unicorns. Given Armstrong's view of instantiation as partial identity, since they are not actually so related, they are necessarily not so related. It is thus in fact impossible for any actual horn and any actual horse to be related in the way that would yield a unicorn. But if so, then the mereological sum of a horn and a horse will clearly fail to ground the possibility of a unicorn. And in that case, how can the mereological sum of a horse and a horn be a truthmaker, minimal or otherwise, for the proposition $<$ It is possible that a unicorn exists $>$ ?

It would not help Armstrong to say instead that the truthmaker for this proposition is the sum of the properties being a horse and being a horn themselves. For these properties are partially identical with the particulars that instantiate them, and since no actual particular instantiates both (i.e., there are no unicorns), no particular could instantiate them either. (If per impossibile a particular did instantiate them, they would not be the properties that they are.)

Finally, the truthmakers for the proposition $<$ It is possible that a unicorn exists $>$ cannot be our concepts of 'horn' and 'horse'. Armstrong distinguishes between conceivability and possibility (1989a: 73-76; 1997: 162-164). The compatibility of the two concepts only establishes the conceivability of a unicorn, whereas the proposition in question is asserting the genuine, metaphysical possibility of the beast itself.

The inability to provide minimal truthmakers for the possibility of unicorns extends to the possibility of counterparts, since counterparts are a special case of aliens. Counterparts are neither identical with, nor constructible out of, actually existing entities. Accordingly, the possibility of counterparts also lacks a minimal truthmaker.

Armstrong might not be too alarmed to discover that his account is incapable of providing minimal truthmakers for alien possibilities. After all, following Read (2000) he claims that certain propositions indeed lack minimal truthmakers. These are truths of infinity. Suppose that there is a denumerable infinity of electrons in the 
world. The proposition $<$ There are infinitely many electrons $>$ is then made true by the totality of electrons. But now consider every third electron in that totality. They make up a sub-totality, which is also infinite, and hence also serves as a truthmaker for the proposition $<$ There are infinitely many electrons $>$. And so on for any $n$th electron we pick, where $n$ is a finite natural number. The upshot is that we never reach a minimal truthmaker for the truth in question.

While the case of denumerably infinite totalities shows that not every truth can have a minimal truthmaker, it does not show that no truth has one. Nor, therefore, does it show that no truth requires a minimal truthmaker. Whether a truth requires a minimal truthmaker, it seems to me, depends on what the truth is about. In the case of truths of infinity, the very nature of infinity explains why there cannot be minimal truthmakers for them. But in the case of most other truths such explanations seem to be absent (and indeed Armstrong takes truths of infinity to be the only ones lacking minimal truthmakers; 2004: 22). Truths about alien possibilities (including counterparts) are a case in point. There is nothing in the nature of aliens and counterparts per se that explains why they should fail to have minimal truthmakers. What their nature does explain is why the attempt to find those truthmakers in the actual world necessarily fails. For, to repeat, aliens are neither identical with, nor combinatorially constructible out of, actually existing entities. To salvage his truthmaking account of alien possibilities, therefore, Armstrong must look for their minimal truthmakers in a realm of merely possible entities. That, however, stands in the way of a genuine reduction of alien possibilities.

It might be thought that Armstrong's failure to provide minimal truthmakers is not in fact as bad as I am suggesting. For as long as he is able to provide non-minimal truthmakers for alien possibilities, he will have succeeded in grounding those possibilities in reality. And this, it will now be said, he can do by applying his Possibility Principle. In the following two sections, however, I will undermine Armstrong's Possibility Principle, and hence his attempt to provide non-minimal truthmakers for alien possibilities in this way.

\section{The Possibility Principle}

Armstrong maintains that the truthmaker for a contingent proposition is also a truthmaker for the possibility of its contradictory. Now, as we have already seen, Armstrong's new view of instantiation renders all genuine true predications as necessarily true. Thus, for any true predication $\langle a$ is $F>$, the contradictory $<a$ is not $F>$ is necessarily false rather than possibly true. This, of course, severely limits the scope of application of the Possibility Principle. Which are the contingent propositions, then, to which the Principle can be applied? While there is no contingency of predication within Armstrong's new scheme, there is nevertheless genuine contingency of existence. Thus, propositions such as <Armstrong exists> and $<$ There are unicorns $>$ are genuinely contingent - the first is contingently true, the second contingently false. (These are genuine propositions, but not genuine predications, since Armstrong does not view existence as a genuine property; cf. Armstrong 2004: 6.) So: the scope of application of the Possibility Principle is restricted to existential propositions. 
Consider, then, the proposition $<$ Armstrong exists $>$. This proposition is contingently true; Armstrong exists, but he could have failed to exist. The Possibility Principle now tells us that the truthmaker for the proposition $<$ Armstrong exists $>$ is also a truthmaker for the proposition $<$ Armstrong is possibly non-existent $>$. Since the former proposition is made true by Armstrong's existence, then it is his existence that also makes the latter proposition true. But this seems wrong. How can the mere existence of Armstrong make it true that his non-existence is also a possibility? Armstrong's existence, after all, leaves open the possibility that he exists necessarily. Put differently, if mere existence entailed the possibility of non-existence, then God, no less than Armstrong, could fail to exist. But God exists necessarily, if he exists at all. So it cannot be mere existence that entails the possibility of non-existence. Armstrong of course regards all existence as contingent, and hence rules out the existence of God. But that is irrelevant. For as long as the notion of necessary existence is coherent (and to my knowledge, Armstrong does not challenge that ${ }^{12}$ ), the point remains that it is not mere existence, and hence not the mere existence of Armstrong, that entails the possibility of nonexistence, and hence that makes it true that Armstrong is possibly non-existent. It is something more specific about (Armstrong's) existence that does that (I return to this in a moment). Note that talk of 'Armstrong's existence' does not presuppose that existence is a genuine property of Armstrong's. If we think of it as a second-order property instead, i.e., as the property of being instantiated, then the thought is that the mere instantiation of the properties involved in the highly complex state of affairs that is Armstrong is not what makes it true that Armstrong is possibly non-existent. After all, those properties may be such that they are necessarily instantiated. And so on.

Now, the first point I want to make here is that while Armstrong's mere existence cannot be what makes the proposition $<$ Armstrong is possibly non-existent $>$ true, it is nevertheless precisely what makes the proposition $<$ Armstrong exists $>$ true. Here we have, therefore, a case where the truthmaker for a proposition is not also a truthmaker for the possibility of its contradictory. What holds for 'Armstrong exists' and 'Armstrong is possibly non-existent' also holds, of course, for countless other pairs of propositions (e.g., 'Bush exists' and 'Bush is possibly non-existent', etc.). The Possibility Principle is therefore false.

In the next section I will suggest another, more fundamental way in which Armstrong's Possibility Principle is false. But now I want to return to the question of what it is specifically about Armstrong's existence that entails the possibility of his non-existence. It will transpire that the Possibility Principle is incapable of underwriting a genuine reduction of possibility, even if it were true.

Why does Armstrong take the truthmaker for the proposition $<$ Armstrong exists $>$ to also be a truthmaker for the proposition <Armstrong is possibly non-existent $>$ ? The answer is that the former proposition is contingently true, and as such entails the truth of the latter proposition. All the plausibility of taking the truthmaker for a true contingent proposition to also be a truthmaker for the possibility of its contradictory derives from the plausibility of taking a true contingent proposition to entail the possibility of its contradictory.

\footnotetext{
${ }^{12}$ Distinguish the coherence of necessary existence from the coherence of God. Even if the latter is deemed incoherent, abstract objects are still plausible candidates for necessary beings. 
Now, we have said that $<$ Armstrong exists $>$ is an existential proposition, i.e., it is a proposition whose content is exhausted by an assertion of existence. Such propositions have the form $<x$ exists $>$, or more perspicuously $<T$ exists $>$, since the objects whose existence they assert also serve as their truthmakers. Propositions of the form $<T$ exists $>$ have unique minimal truthmakers, according to Armstrong (2004: 23). To say that $T$ is a minimal truthmaker for $<T$ exists $>$ is to say that nothing can be taken away from $T$ and the remainder still be a truthmaker for that proposition. And to say that $T$ is a unique minimal truthmaker for $<T$ exists $>$ is to say that $T$ is the only minimal truthmaker for that proposition. ${ }^{13}$ So, take anything away from $T$, or remove $T$ altogether, and $<T$ exists $>$ is no longer true. Now, $T$ exists only contingently, since Armstrong takes all existence to be contingent. But since $T$ is the unique minimal truthmaker for $<T$ exists $>$, it follows that $T$ not only makes for the truth of $<T$ exists $>$, but also for its contingency. For as a contingent being, $T$ could fail to exist, and if it did, nothing else would make $<T$ exists $>$ true. The proposition $<T$ exists $>$ is contingently true, therefore, because $T$ itself is a contingent being. This claim generalizes to all propositions of the form $<T$ exists $>$. Their contingency derives from the contingent existence of the $T$ in question.

I am not claiming here that for any true proposition $p$ and its truthmaker $T$, the contingency of $T$ entails the contingency of $p$. This is, indeed, false, since (e.g.) the proposition $<$ Armstrong exists or Armstrong does not exist $>$ is necessarily true, but is presumably made true by Armstrong, a contingent being. ${ }^{14}$ The proposition $<$ Armstrong exists or Armstrong does not exist>, however, is not an existential proposition the form of $<T$ exists $>$, and it is only of propositions with that form that I am claiming that they derive their contingency from the contingency of their truthmakers. In short, then, the contingency of a proposition derives from the contingency of its truthmaker plus the form of the proposition itself. ${ }^{15}$

Now, since for any true existential proposition $p$, the possibility of not- $p$ is grounded in the contingency of $p$, and the contingency of $p$ is in turn partly grounded in the contingency of its truthmaker, $T$, it follows that the possibility of not- $p$ is itself partly grounded in the contingency of $T$. But, and now I get to my point, contingency is a modal notion through and through. To say that an entity is contingent is to say that it is possible for it to exist and also possible for it not to exist. So, what makes it true that

\footnotetext{
13 Any non-minimal truthmaker for $<T$ exists $>$ must therefore have $T$ as a part or constituent.

${ }^{14}$ I thank the referee for this journal for raising this issue. It is actually questionable whether $<$ Armstrong exists or Armstrong does not exist $>$ is made true by Armstrong. For this proposition is not so much true in virtue of Armstrong's existence or non-existence as true regardless of his existence or non-existence. In other words, $<$ Armstrong exists or Armstrong does not exist $>$ is arguably true in virtue of its logical form alone. <Armstrong exists or Armstrong does not exist $>$ is an instance of the law of the excluded middle, and it is plausible to take instances of the law to inherit their truth from the truth of the law itself (what, in turn, makes the law true is another matter). But even if this correct, there are other necessary truths of a disjunctive form that are made true by Armstrong. The proposition $<$ Armstrong exists or $2+2=4>$ is one such example. (This proposition is, of course, also made true by the truthmaker for the disjunct $<2+2=4>$ ).

${ }^{15}$ Strictly speaking, not all contingent propositions are of the form $<T$ exists $>$. But those contingent propositions that are not of this form must nevertheless themselves contain a proposition that is of that form, and from which they then derive their contingency. Thus, $<x$ exists or $y$ exists $>$ is a contingent proposition because its disjuncts $<x$ exists $>$ and $<y$ exists $>$ are themselves of the form $<T$ exists $>$, and as such are contingent. The same is true for the proposition $<x$ exists and $2+2=4>$. This proposition is contingent because one of its conjuncts, $<x$ exists $>$, is a contingent proposition of the form $<T$ exists $>$.
} 
Armstrong is possibly non-existent is ultimately... well, in part that he is possibly nonexistent! The possibility of Armstrong's non-existence has clearly not been grounded in a non-modal feature of Armstrong (or of anything else). To the extent, therefore, that it is partly the contingency of Armstrong's existence that makes it true that Armstrong is possibly non-existent, and more generally, to the extent that it is in part the contingent nature of truthmakers for existential truths that grounds the corresponding truths of mere possibility, truthmaking theory cannot underwrite a genuine reduction of possibility. It cannot do so, for the truthmakers it appeals to are in fact themselves modal in nature. (The truthmakers are not merely the objects - e.g., not merely Armstrong - but their contingent existence. ${ }^{16}$ )

\section{The Entailment Principle}

In the previous section, I argued that the Possibility Principle is false, since the truthmaker for, say, the proposition $<$ Armstrong exists $>$ cannot plausibly be taken to be also a truthmaker for the possibility of his non-existence. There is, however, a more fundamental way in which the Possibility Principle is false. The principle, as we have seen, is an application of the Entailment Principle to truths of mere possibility. The trouble is that the Entailment Principle is itself false; it is false even when the Principle is Jackson-amended or when its application is so restricted as to prevent contingent propositions from entailing every necessary truth. The argument, due to Rodriguez-Pereyra (2006), is exceedingly simple. Consider the conjunctive proposition $<\mathrm{I}$ am hungry and water boils at 100 degrees Celsius $>$. ${ }^{17}$ This proposition entails $<$ I am hungry $>$. So, by the Entailment Principle, the truthmaker for $<$ I am hungry and water boils at 100 degrees Celsius $>$ is also a truthmaker for $<\mathrm{I}$ am hungry $>$. But that is just false. As we have already said, a truthmaker for a given proposition is that portion of reality in virtue of which the proposition is true. Accordingly, the truthmaker for $<\mathrm{I}$ am hungry $>$ is that portion of reality in virtue of which I am hungry. But I am not hungry in virtue of the state of affairs of my being hungry and water's boiling at 100 degrees Celsius. I am hungry solely in virtue of my being hungry. (The boiling point of water is simply irrelevant; I could conceivably be hungry and water boil at, say, 101 degrees Celsius instead.) The Entailment Principle is thus false. It is false because it treats truthmaking as merely a relation of necessitation. While a conjunctive state of affairs necessitates the truth of a proposition, it does not follow that the proposition is true in virtue of that conjunctive state of affairs. Truthmaking is a more fine-grained relation than mere necessitation. ${ }^{18}$

\footnotetext{
${ }^{16}$ Again, this does not presuppose that existence is a genuine property of objects. If we take existence to be the second-order property of being instantiated instead, then the contingency of (say) Armstrong's existence amounts to the conjunction of Armstrong's properties having instances only contingently.

${ }^{17}$ Rodriguez-Pereyra uses a different example.

18 This point is reminiscent of Kit Fine's insight that essence is a more fine-grained notion than necessity. Socrates, for example, is necessarily a member of the singleton Socrates \{Socrates\}, since he could not exist without being member of that set. But he is not essentially a member of the singleton \{Socrates\}, since Socrates is not what he is in virtue of being a member of that set (see Fine 1994).
} 
Armstrong himself discusses a related objection, namely that strictly speaking there are only minimal truthmakers.

For, it may be argued, a non-minimal truthmaker involves redundancy, and the truth in question may not be true in virtue of the redundant material. This is a possible way to go, but I think that it is methodologically an unwise choice, for similar reasons to the logician's practice of taking 'some' not to exclude 'all'. In actual philosophical investigations it can be difficult to delineate the minimal truthmaker precisely while still being able to point to truthmakers that are nonminimal. But if someone wishes to say that what I call a non-minimal truthmaker for a certain proposition is really a portion of reality that has the real truthmaker as a proper part, then I have no metaphysical objection (2004: 20-21).

There are several things to note here. First, the objection against the Entailment Principle is not that only minimal truthmakers are genuine truthmakers. One can accept that certain propositions lack minimal truthmakers while denying that what appear to be non-minimal truthmakers for others are in fact truthmakers for them at all. Secondly, it does not follow from the fact that it might be 'difficult to delineate the minimal truthmaker precisely' for a given true proposition, that the larger portion of reality containing it is itself a truthmaker for that proposition. For what is true in virtue of the part need not be true in virtue of the whole. $<$ Paris is beautiful $>$ is true in virtue of Paris, not in virtue of France, even though Paris is a part of France. Thirdly, the issue here is neither terminological nor methodological, as Armstrong seems to imply, but metaphysical. For truthmaking is an 'in-virtue-of' relation, and to take the state of affairs of my being hungry and water's boiling at 100 degrees Celsius to be a truthmaker for 'I am hungry' is simply to misunderstand the nature of such relations.

Our counterexample to the Entailment Principle, like those given by RodriguezPereyra, exploits the conjunctive nature of certain propositions. But there are counterexamples to the principle that do not involve conjunctive propositions at all. Assume, as seems plausible, that for any object $x, x$ has a shape if and only if $x$ has a size ${ }^{19}$ (at least assume this when the values of ' $x$ ' are restricted to macroscopic objects). Take, then, any such object $x .<x$ has a size $>$ entails $<x$ has a shape $>$. By Armstrong's Entailment Principle, the truthmaker for the former proposition is also a truthmaker for the latter. Suppose that the truthmaker for $<x$ has a size $>$ is the state of affairs of $x$ 's being 2 square meters. Then $x$ 's being 2 square meters is also a truthmaker for the proposition $<x$ has a shape $>$. But it is surely implausible to say that it is in virtue of $x$ 's being 2 square meters, that $<x$ has a shape $>$ is true - being 2 square meters is after all a size, not a shape. Rather, $<x$ has a shape $>$ will be true in virtue of, say, $x$ 's being rectangular instead. The Entailment Principle is thus false. Once again, it is false because truthmaking is a more fine-grained relation than that of mere necessitation. ${ }^{20}$

\footnotetext{
${ }^{19}$ Armstrong himself makes this assumption in earlier work (cf. 1978).

${ }^{20}$ As Rodriguez-Pereyra shows, the Entailment Principle cannot be saved by adopting a relevant notion of entailment. Systems T, R and E of relevant logic all validate the entailment ' $(\mathrm{P} \& \mathrm{Q}) \rightarrow \mathrm{P}$ '. It is true that connexive logic does not validate that entailment, since it takes the relation of entailment to be determined by meanings rather than truth-values. But that notion of entailment is irrelevant to truthmaking theory, since truthmaking is an ontological rather than a semantic relation (for details, see Rodriguez-Pereyra 2006, sections 7 and 8).
} 
At the start of this final section, I remarked that the Possibility Principle is an application of the Entailment Principle to truths of mere possibility. Since the Entailment Principle is false, it follows that the Possibility Principle is also false. Without the Possibility Principle, however, Armstrong is left with no provision of non-minimal truthmakers for truths of mere possibility. At the same time, Armstrong's attempt to provide minimal truthmakers for such possibilities also foundered. It follows, therefore, that Armstrong has failed to provide any truthmakers for truths of mere possibility. This seriously undermines Armstrong's truthmaking account of modality.

Acknowledgements I wish to thank Hanjo Glock for comments on a previous draft of this paper.

\section{References}

Armstrong, D. (1978). Universals and scientific realism: A theory of universals. Cambridge: Cambridge University Press.

Armstrong, D. (1989a). A combinatorial theory of possibility. Cambridge: Cambridge University Press. Armstrong, D. (1989b). Universals: An opinionated introduction. Boulder, Colorado: Westview Press.

Armstrong, D. (1997). A world of states of affairs. Cambridge: Cambridge University Press.

Armstrong, D. (2004). Truth and truthmakers. Cambridge: Cambridge University Press.

Armstrong, D. (2005). Reply to Simons and Mumford. Australasian Journal of Philosophy, 83, 271-276.

Baxter, D. (2001). Instantiation as partial identity. Australasian Journal of Philosophy, 79, 449-464.

David, M. (2002). Armstrong on truthmaking. In H. Bebee, \& J. Dodd (Eds.), Truthmakers: The contemporary debate (pp. 141-159). Oxford: Clarendon Press.

Fine, K. (1994). Essence and modality. In J. Tomberlin (Ed.), Philosophical perspectives, 8, Logic and language (pp. 1-16). Atascadero, CA: Ridgeview Publishing.

Lewis, D. (1986). On the plurality of worlds. Oxford: Blackwell.

Mumford, S. (2005). The true and the false. Australasian Journal of Philosophy, 83, 263-269.

Mumford, S. (2007). David Armstrong. UK: Acumen.

Read, S. (2000). Truthmaking and the disjunction thesis. Mind, 109, 67-79.

Rodriguez-Pereyra, G. (2006). Truthmaking, entailment, and the conjunction thesis. Mind, 115, 957-982.

Simons, P. (2005). Negatives, numbers, and necessity: Some worries about Armstrong's version of truthmaking. Australasian Journal of Philosophy, 83, 253-261. 